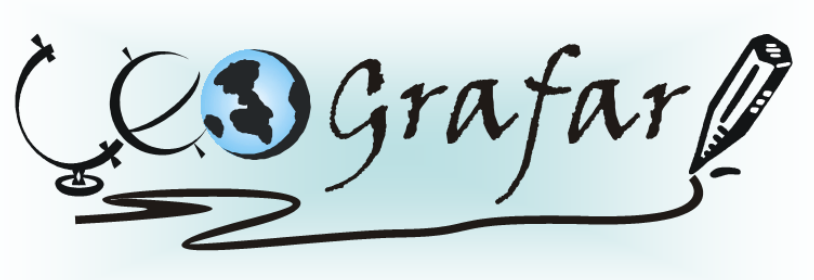

Revista Eletrônica do Programa de Pós-Graduação em Geografia - UFPR

\title{
TRAJETÓRIA GEOGRÁFICA: A BUSCA PELAS CONEXÕES
}

\author{
(Pesquisador convidado) \\ João Osvaldo Rodrigues Nunes \\ Professor Livre Docente - Departamento de Geografia, FCT/UNESP \\ joaosvaldo@fct.unesp.br
}

\section{Resumo}

No presente texto, apresento a minha trajetória acadêmica que tenho percorrido como geógrafo, bem como as referências bibliográficas que influenciaram meu percurso na busca pela interação entre as dinâmicas da sociedade e da natureza no espaço geográfico. Para isso, tomou-se como base o materialismo histórico e dialético e o pensamento complexo na construção de uma Geografia, que caminhe para a conjunção entre os saberes das áreas ambientais (Geografia Física) e das humanidades (Geografia Humana). É pela práxis que tenho realizado um modo de fazer Geografia que permite ao conhecimento ir para além da divisão entre o físico e o humano, no escopo da ciência geográfica.

Palavras-chaves: Dialética materialista; Geografia; Natureza; Práxis; Pensamento complexo; Sociedade.

\section{Introdução}

O presente texto é o resultado de uma trajetória que se inicia no curso de graduação em Geografia, na Universidade Federal do Rio Grande do Sul, em especial com o estudo da dinâmica de formação dos areais no município de São Francisco de Assis (RS). Posteriormente, passa pela pósgraduação em Geografia, na Faculdade de Ciências e Tecnologia da Universidade Estadual Paulista, com a tese de doutorado que versou sobre o estudo de áreas adequadas à construção de aterros sanitários, e culmina com a atuação docente no Departamento de Geografia da FCT/UNESP, Campus de Presidente Prudente (SP).

Nessa trajetória, o objetivo principal, através da práxis acadêmica realizada nas disciplinas de Geomorfologia e Geomorfologia ambiental, sempre foi mostrar a interdisciplinaridade entre os conhecimentos geomorfológicos e a Geografia, tendo como suporte o método dialético materialista e a sua conjunção com a dialógica do pensamento complexo. 
O enlace para essa conjunção é a práxis (VÁZQUES, 2007) vinculada ao materialismo histórico e dialético, em que a PRÁTICA, através da teoria, guia a ação, e a TEORIA transforma a ação em algo consciente (MARX; ENGELS, 2002; FOSTER, 2005). Ambas se materializam no espaço geográfico, no qual o relevo, através das suas diferentes morfologias e rugosidades, transforma-se ao longo do tempo geológico e histórico, em decorrência das dinâmicas da natureza e da sociedade, sendo a desta última concretizada nos chamados depósitos tecnogênicos (PELOGGIA, 1998; PELOGGIA et al., 2014a; 2014b).

A práxis a partir da perspectiva do materialismo histórico coloca-se aqui como ontológica, porque define os limites da objetividade e da subjetividade, quando o autor do conhecimento, por meio deste, age na natureza e a transforma em produto, transformando-se também em sujeito (MARTINS, 2007). É um processo dialético em que a teoria e a ação somente se materializam quando existe a conexão dos fenômenos em sua totalidade. Sem a correlação entre os fatores físicos e humanos não existe a formação do próprio ser humano, fato que só se concretiza quando se aborda a totalidade, pois, sem a ação conjuntiva, não se alcança a própria natureza, que é física e social (MOREIRA, 2011).

Dessa forma, minha trajetória como geógrafo, desde a graduação, tem como base 0 materialismo histórico e dialético, bem como, ultimamente, a influência do pensamento complexo (MORIN, s. d.; SILVA; GALEANO, 2004), na construção de uma Geografia que caminhe para a conjunção entre os saberes das áreas ambientais (Geografia Física) e das humanidades (Geografia Humana) (LEFF, 2002).

A união do pensamento complexo à dialética materialista é o eixo principal, associado ao conceito de práxis. É pela práxis (GORENDER, 1988) que tenho realizado um modo de fazer Geografia que permite ao conhecimento, no escopo da ciência geográfica, ir para além da divisão entre o físico e o humano (NUNES, 2014).

A junção do pensamento dialético materialista com o da complexidade permite a transformação da natureza e, com ela, a do sujeito, pela ação que interpreta as interconexões dos fenômenos (HUMBOLDT, 1965a; 1965b; 2005). Se a modernidade foi o momento da construção disciplinar divisão entre sujeito e objeto (DESCARTES, 1998; ROSSI, 2001) - nela ocorreu o surgimento do materialismo histórico e, posteriormente, do pensamento complexo, que não nega as dimensões "espirituais" do sujeito no conhecimento, ou seja, a atividade subjetiva. Neste aspecto, enquanto a pósmodernidade apresenta-se como a TESE, a dialética materialista e a complexidade configuram a ANTÍTESE, e a práxis a SÍNTESE. 


\section{A trajetória acadêmica}

Iniciei meus estudos acadêmicos no ano de 1987, quando, ingressei na Universidade Federal do Rio Grande do Sul. O primeiro fato marcante foi a aula inaugural, ministrada pelo professor Aziz Nacib Ab'Saber, que proferiu uma palestra sobre os domínios morfoclimáticos brasileiros. A partir daquele momento, as obras de Ab'Saber (1958; 1969; 2004) tornaram-se leitura obrigatória para compreensão das paisagens brasileiras, bem como de seus problemas ambientais decorrentes das formas de ocupação (CASSETI, 1991).

Todavia, o verdadeiro despertar no curso de Geografia acabou por acontecer no segundo semestre de 1987, quando, em uma das tantas viagens que fazíamos ao interior do Estado do Rio Grande do Sul, conheci a professora Dirce Maria Antunes Suertegaray, que iria mudar totalmente a minha forma de pensar e fazer Geografia e Geomorfologia.

Como eu tinha o desejo de trabalhar em áreas que envolvessem atividades práticas, ou seja, 0 manuseio do solo e das rochas, identifiquei-me rapidamente com a professora Dirce, que lecionava Geomorfologia. Assim, passei a dedicar-me, tanto na parte teórica como prática, às diversas atividades da disciplina. Esse esforço de dedicação foi recompensado, primeiramente, com uma bolsa de monitor da disciplina de Geomorfologia e, mais tarde, com uma bolsa de iniciação científica, concedida pelo CNPq. A busca pelo constante aprendizado, não somente em Geomorfologia mas também em áreas afins, levou-me a frequentar algumas disciplinas no Departamento de Geologia: dentre elas destaco a de Sedimentogênese, ministrada pelo professor Dr. Heinrich Th. Frank.

Sob a orientação da professora Dirce, e em conjunto com a colega geógrafa, Nina Simone Vilaverde Moura, passamos a desenvolver um projeto de estudo sobre a gênese dos areais nos municípios de Alegrete e São Francisco de Assis, a partir da perspectiva geomorfológica (SUERTEGARAY, 1988).

Coube a mim a responsabilidade sobre a parte do projeto referente ao município de São Francisco de Assis. Os estudos desenvolvidos nessa área resultaram em duas premiações de Honra ao Mérito pela participação nos dois primeiros eventos do Salão de Iniciação Científica promovidos pela Universidade Federal do Rio Grande do Sul, nos anos de 1989 e 1990. No final de 1990, como último ano da graduação, defendi a monografia de conclusão do curso de bacharelado com o título $\underline{A}$ pesquisa em Geomorfologia como prática acadêmica: a desertificação em São Francisco de Assis.

Do início de 1991 até setembro de 1998 morei no Japão. No período em que lá estivemos, minha esposa e eu produzimos o livro JAPÃO, publicado pela Editora Ática, que fazia parte da coleção Viagem pela Geografia, e concorreu ao prêmio Jabuti, no ano de 1998, ficando entre os dez melhores de sua categoria paradidáticos, em nível nacional. 
Após esse período, em setembro de 1998 retornamos definitivamente para o Brasil, pois recebi um convite para trabalhar na Secretaria Municipal do Meio Ambiente do município de Presidente Prudente (SP), com a função de escolher a área que deveria receber as instalações do Aterro Sanitário da cidade.

No final do ano de 1998, recebi outro convite: para trabalhar como Professor Assistente I na Fundação Universidade Estadual do Tocantins - UNITINS, na cidade de Araguaína, lecionando as disciplinas: Introdução ao Pensamento Geográfico, Climatologia, Biogeografia, Geografia Agrária e Geografia Regional.

Como ainda não tinha realizado a pós-graduação, resolvi prestar o exame de seleção para 0 mestrado e doutorado no curso de pós-graduação em Geografia da FCT/UNESP - Presidente Prudente em 1999, sendo aprovado e orientado pelo professor Dr. João Lima Sant'Anna Neto a partir de 2000.

No período da pós-graduação destaco um artigo, produzido no ano de 2001, em conjunto com a professora Doutora Dirce Maria Antunes Suertegaray, publicado na Revista Terra Livre, no 17, sob o título A natureza da Geografia Física na Geografia (SUERTEGARAY; NUNES, 2001).

Em abril de 2002 defendi a tese de doutorado, sob o título Uma contribuição metodológica ao estudo da dinâmica da paisagem aplicada à escolha de áreas para a construção de aterro sanitário em Presidente Prudente - SP (NUNES, 2002).

Posteriormente, como professor concursado no Departamento de Geografia da Faculdade de Ciências e Tecnologia da UNESP, Campus de Presidente Prudente, recebi a incumbência de coordenar o Laboratório de Sedimentologia e Análise de Solos, onde, junto com a professora Maria Cristina Perusi, começamos a desenvolver projetos de pesquisa, ensino e extensão, com ênfase nas áreas de Pedologia e Geomorfologia.

Merece destaque o Projeto de Extensão Trilhando Pelos Solos, em que passamos a realizar um trabalho que envolve, direta e indiretamente, no ensino de solos e áreas afins, os alunos dos cursos de Geografia, Engenharia Ambiental, Arquitetura, Pedagogia etc., recebendo visitas de estudantes das escolas públicas e privadas da região, dos níveis fundamental, médio, técnico e superior, bem como ir às escolas, sempre divulgando os conhecimentos sobre solos.

No início de 2003 recebi uma bolsa de recém-doutor (PRODOC), desenvolvendo o projeto de pesquisa intitulado Planejamento ambiental: análise comparativa de Argissolos e Latossolos pelo método da homogeneização do perfil para a obtenção do material de cobertura de aterros sanitários e controlados para a região de Presidente Prudente e municípios do Oeste Paulista.

O projeto tratava de estudo envolvendo solos e geomorfologia, com aplicação na escolha de áreas adequadas para aterros sanitários. 0 objetivo era comparar as características texturais de dois 
tipos de solos, os Latossolos e os Argissolos ao longo de seus respectivos perfis pedológicos, e verificar se os Argissolos apresentavam condições de ser utilizados como materiais de cobertura para aterros sanitários e controlados.

Durante o período de desenvolvimento do projeto tive a oportunidade de conhecer melhor os aspectos ambientais (relevo, geologia, solos, etc) dos municípios de Presidente Prudente, Pirapozinho, Álvares Machado, Regente Feijó e Anhumas, pois o trabalho previa a coleta de várias amostras de solos, associada à identificação dos compartimentos de relevo. Foi nesse primeiro contato com 0 campo que pude conhecer melhor o sério quadro de degradação ambiental instalado, principalmente as erosões lineares (sulcos, ravinas e voçorocas) existentes na região administrativa de Presidente Prudente.

Em 2004 ingresso no programa de pós-graduação em Geografia da FCT/UNESP, orientando alunos no mestrado e doutorado nas áreas de mapeamento geomorfológico, recuperação de áreas degradas por erosão pluvial, ensino de Geografia Física (relevo e solos) e epistemologia ambiental.

Neste ínterim, junto com professores do Departamento de Cartografia, começamos a estimar 0 grau de aptidão de áreas do município de Presidente Prudente para a instalação de aterros sanitários. Utilizamos os conhecimentos de geoprocessamento, através de Sistemas de Informação Geográfica (SIG), para realizar o tratamento, a manipulação e a análise dos dados, somados ao conhecimento de campo nas áreas de Geomorfologia, Pedologia e Geologia que havia desenvolvido durante minha tese de doutorado.

Para o zoneamento de aptidão da área, foram necessárias a elaboração e a integração de mapas que contêm informações de geomorfologia, pedologia/geologia, hidrogeologia e de uso e cobertura do solo, bem como a utilização das funções de pertinência fuzzy para a padronização das variáveis, e do método AHP (Analytical Hierarchy Process) para a atribuição dos respectivos pesos. A técnica desenvolvida para a área do perímetro urbano da cidade de Presidente Prudente foi posteriormente utilizada no EIA/RIMA do aterro sanitário do município (SAMIZAWA et al., 2006).

Em relação às produções acadêmicas de cunho teórico, em 2006 e 2007, junto com alguns colegas que trabalham com a dinâmica da natureza, foram produzidos dois artigos, sendo eles: Geografia e Ambiente: reflexões sobre o atual momento da Geografia Física (AMORIM; NUNES, 2006) e $\underline{A}$ influência dos métodos científicos na Geografia Física (NUNES et al., 2007). Ambos foram resultantes de reflexões sobre os métodos de pensamento, as categorias e os conceitos geográficos (SANTOS, 1996; 2012). Nesses artigos procurou-se esboçar uma discussão teórica analisando a influência do método dialético materialista e sistêmico (MONTEIRO, 2000) de produção do conhecimento sobre as pesquisas dos geógrafos na área física. 
Todavia, como professor e pesquisador na área de Geomorfologia, junto com o Professor Dr. Paulo Cesar Rocha, organizamos um livro que abordasse de forma mais atenta os aspectos metodológicos e técnicos com as diversas aplicações propositivas dos estudos geomorfológicos no espaço geográfico. Assim, em 2008, é publicado pela Editora Expressão Popular o livro Geomorfologia: Aplicação e Metodologias (NUNES; ROCHA, 2008).

Durante o período entre 01 de outubro de 2008 a 31 de janeiro de 2009 tive a oportunidade de realizar o estágio de pós-doutoramento na Universidade de Alicante (Espanha). O convite surgiu de um convênio firmado entre essa instituição e a FCT/UNESP, sob a coordenação do professor Bernardo Mançano Fernandes. O colega Bernardo convidou-me a participar do projeto Ambiente $\mathrm{e}$ sustentabilidade do uso da terra nos assentamentos rurais da região Ocidental Paulista. Uma possível comparação com as experiências europeias, no qual desenvolvi o subprojeto Análise ambiental e agrária da multifuncionalidade da terra na Província de Alicante - Espanha, sob a supervisão do professor Dr. José Antonio Segrelles Serrano, do Departamento de Geografia Humana da Universidade de Alicante.

O objetivo principal do estágio de pós-doutoramento foi estudar os aspectos ambientais, compreendendo o funcionamento dos sistemas de irrigação (regadíos) utilizados na Província de Alicante, em virtude de ser considerada uma das regiões com menor regime pluvimétrico da Espanha. Também, devido às suas características naturais, tem sofrido nos últimos anos, enormes transformações paisagísticas decorrentes do avanço de projetos especulativos relacionados à expansão turística e imobiliária, cujo resultado é a diminuição das áreas destinadas à agricultura e pecuária e a exploração desmedida dos recursos hídricos superficiais e de subsuperfícies.

Dois anos após o retorno ao Brasil, junto com colegas da UNESP/Campus Ourinhos, desenvolvemos 0 projeto Identificação de áreas degradadas por erosão hídrica e utilização de metodologias alternativas para recuperação de focos erosivos em áreas piloto no Assentamento Rural Nova Esperança do município de Euclides da Cunha - SP (NUNES et al., 2010), com apoio financeiro da CAPES n02/2010 - Ciências Humanas, Sociais e Sociais Aplicadas.

Esse projeto tornou-se a materialização de um desejo profissional que alimentava desde os tempos da graduação na UFRGS, ou seja, poder auxiliar os assentados rurais no equacionamento dos problemas relacionados à erosão e manejo inadequado dos solos, aplicando os conhecimentos geomorfológicos adquiridos nos diversos trabalhos realizados nos areais do Sudoeste do Rio Grande do Sul, na cidade de São Francisco de Assis. Associado ao intento pessoal, havia também a necessidade de regularizar ambientalmente os assentamentos rurais, por parte do INCRA e ITESP, em 
especial as áreas de Reserva Legal e de Proteção Permanente, mormente porque, até o presente momento, todos os quinze assentamentos do Pontal do Paranapanema continuam irregulares.

Foram dois anos de intenso trabalho de campo, a maior parte das vezes, nos finais de semana, período no qual o envolvimento com os assentados, em muitos momentos, articulou o diálogo de saberes da academia com os do cotidiano das pessoas simples do trato com a terra. A experiência então vivenciada fortaleceu laços de amizade entre os colegas do grupo, bem como ampliou a linha de pesquisa vinculada à recuperação de áreas degradadas por processos erosivos, com os pequenos produtores rurais da região de Presidente Prudente e de Marília (SP).

A partir desse projeto, vários orientandos da graduação e da pós-graduação desenvolvem pesquisas nessa área, procurando unir teoria e prática em suas práxis.

Ainda em 2010, juntamente com o Professor Dr. Júlio Kiyoshi Hasegawa, do Departamento de Cartografia da FCT/UNESP, vêm sendo desenvolvidos projetos de mapeamento geomorfológico aplicando técnicas de estereoscopia digital, que permite vetorizar, na tela do computador, informações sobre imagens de satélite ALOS/PRISM, de modo tridimensional.

Outro fato marcante foi a aprovação do Projeto Monitoramento e controle de erosões marginais de reservatórios hidrelétricos: métodos de avaliação dos processos, uso de geotecnologias para seu monitoramento e experimentação de técnicas de controle, resultante de convênio firmado entre a UNESP e a empresa Duke Energy, cuja responsabilidade, nesse projeto, foi pesquisar as características geomorfológicas e pedológicas que influenciam no solapamento das margens dos reservatórios das usinas hidroelétricas de Rosana e Chavantes, no Rio Paranapanema.

O desenvolvimento das ações possibilitou a realização de vários trabalhos de campo, os quais permitiram, por sua vez, profícua troca de experiência profissional com colegas de outras áreas e a introdução de alunos dos cursos de graduação no campo da pesquisa, favorecendo, desde cedo, sua inserção no âmbito profissional.

Assim, ao longo de minha trajetória como geógrafo, tenho elaborado um pensamento amplo e plural, em que tomamos o método dialético do materialismo histórico como vetor condutor, relacionado à dialógica do pensamento complexo, procurando aplicar nos estudos geográficos e geomorfológicos, inter-relacionando dinâmica da natureza e dinâmica da sociedade. A profusão de interações na busca dessa conjunção está expressa na Figura 1, onde se apresentam as referências históricas que influenciaram a construção de um pensar dialético que, ao conjugar teoria e prática, materializa-se em uma práxis diferenciada. 
Figura 01: Representação da trajetória teórica e do método de construção do pensamento geográfico.

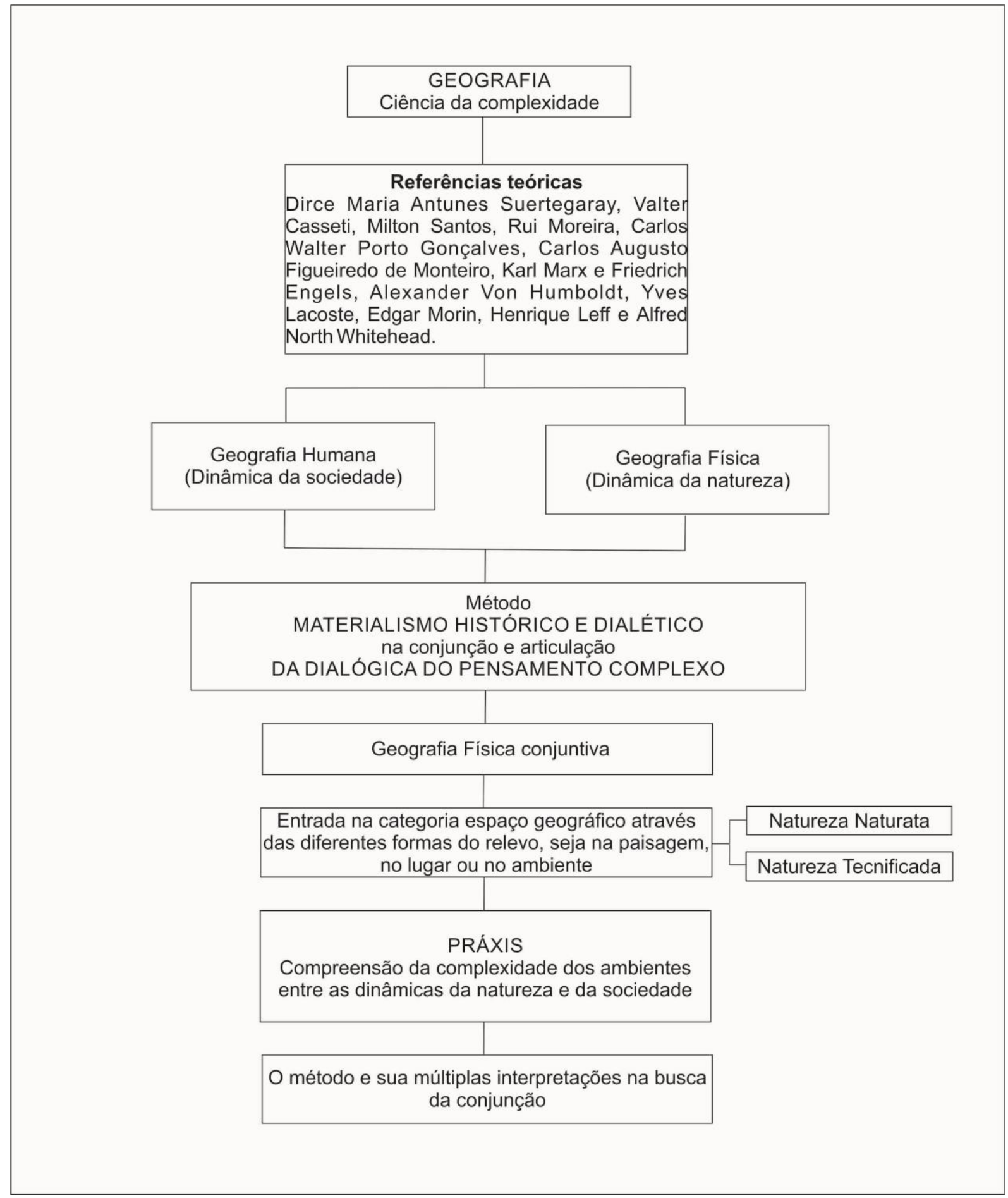

Fonte: 0 autor.

\section{Referências}

AB'SABER, A. N. Geomorfologia do sítio urbano de São Paulo. In: Boletim da Faculdade de Filosofia, Ciências e Letras da USP, São Paulo, n. 219, 1957. (Geografia, 12) [Publicação da Tese (Doutorado) Faculdade de Filosofia, Letras e Ciências Humanas, Universidade de São Paulo, São Paulo, 1956.] 
AB' SABER, A. N. Um conceito de Geomorfologia a serviço das pesquisas sobre o Quaternário. In: Geomorfologia, São Paulo, n. 18, p. 1-23, 1969.

AB'SABER, A. N. São Paulo - Ensaio e entrevero. São Paulo: EDUSP/Imprensa Oficial do Estado de São Paulo, 2004.

AMORIM, M. C. C. T.; NUNES, J. O. R. Geografia e ambiente: reflexões sobre o atual momento da geografia física. In: Geografia: Rio Claro, v. 31, n. 2, 2006.

CASSETI, V. Ambiente e apropriação do relevo. São Paulo: Contexto, 1991.

DESCARTES, R. Discurso sobre o método: para bem dirigir a própria razão e procurar a verdade nas ciências. São Paulo: Ed. Hemus, 1998.

FOSTER, J. B. A ecologia de Marx: materialismo e natureza. Rio de Janeiro: Ed. Civilização Brasileira, 2005.

GONÇALVES, C. W. P. Os (Des)Caminhos do meio Ambiente. São Paulo: Contexto, 1989.

GORENDER, J. Uma vida de teoria e práxis: uma entrevista com Jacob Gorender. Revista Arrabaldes, ano I, nº 1-2, set./dez. 1988, p. 135-154.

HUMBOLDT, A. V. Cosmos o ensaio de uma descripción física Del mundo. Córdoba-ES: Servicio de Publicaciones de la Universidad de Córdoba, 2005. Livros I e II.

HUMBOLDT, A. V. Quadros da Natureza (a). Vol. 1. Trad. Assis Carvalho. Rio de Janeiro: W. M. Jackson Inc., 1965.

HUMBOLDT, A. V. Quadros da Natureza (b). Vol. 2. Trad. Assis Carvalho. Rio de Janeiro: W. M. Jackson Inc., 1965.

LACOSTE, Y. A geografia - isso serve, em primeiro lugar para fazer guerra. Trad. Maria Cecília França. Campinas: Papirus, 1988.

LEFF, E. Epistemologia ambiental. $2^{\mathrm{a}}$ ed. São Paulo: Cortez, 2002.

MARTINS, E. R. Geografia e ontologia: o fundamento geográfico do ser. In: GEOUSP - Espaço e Tempo, São Paulo, nº 21, p. 33-51, 2007.

MARX, K.; ENGELS, F. A ideologia alemã. Trad. Luis Claudio de Castro e Costa. São Paulo: Martins Fontes, 2002.

MONTEIRO, C. A. F. Geossistemas: a história de uma procura. (Novas abordagens 3). São Paulo: Contexto/GeoUSP, 2000.

MORIN, E. Ciência com Consciência. Mem. Martins: Publicações Europa-América, s. d.

MOREIRA, R. Para onde vai o pensamento geográfico? Por uma epistemologia crítica. São Paulo: Contexto, 2011.

NUNES, J. O. R. Uma contribuição metodológica ao estudo da dinâmica da paisagem aplicada a escolha de áreas para construção de aterro sanitário em Presidente Prudente - SP. 2002. 209p. Tese (Doutorado em Geografia) - Faculdade de Ciência e Tecnologia, Universidade Estadual Paulista, Presidente Prudente.

NUNES, J. O. R. et al. A influência dos métodos científicos na Geografia Física. In: Revista Terra Livre, $n^{0}$ 27, volume 2, série 27. São Paulo, Associação dos Geógrafos Brasileiros, 2007, p. 121-132.

NUNES, J. O. R.; ROCHA, P. C. Geomorfologia: aplicação e metodologias. São Paulo: Editora Expressão Popular, 2008.

NUNES, J. O. R.; PERUSI, M. C.; PIROLI, E. L.; TOMMASELI, J. T. G.; HESPANHOL, A. N. Identificação de áreas degradadas por erosão hídrica e utilização de metodologias alternativas para recuperação de focos erosivos em áreas piloto no Assentamento Rural Nova Esperança do Município de Euclides da Cunha - SP. Edital CNPQ n 02/2010, Presidente Prudente, maio de 2010.

NUNES, J. O. R. Práxis geográfica e suas conjunções. 2014. 150p. Tese (Livre Docência). Faculdade de Ciência e Tecnologia, Universidade Estadual Paulista, Presidente Prudente.

PELOGGIA, A. O homem e o ambiente geológico: geologia, sociedade e ocupação urbana no município de São Paulo. São Paulo: Xamã, 1998. p. 20; 34; 73-4. 
PELOGGIA, A. U. G.; OlIVEIRA, A. M. S.; OLIVEIRA, A. A.; SILVA, E. C. N.; NUNES, J. O. R. Technogenic geodiversity: a proposal on the classification of artificial ground. In: Revista Quaternary and Environmental Geosciences, Curitiba, v. 5, n. 1, p. 28-40, 2014. Disponível em: $<$ http://ojs.c3sl.ufpr.br/ojs2/index.php/abequa/article/view/34823>. Acesso em: 07 dez. 2014.

ROSSI, P. O nascimento da ciência moderna na Europa. São Paulo: Ed. EDUSC, 2001.

SAMIZAVA, T. M.; NUNES, J. O. R.; IMAI, N. N.; KAIDA, R. H. SIG aplicado à avaliação de áreas para instalação de aterro sanitário no município de Presidente Prudente - SP. In: PLURIS - $2^{\circ}$ Congresso Luso Brasileiro para o Planejamento, Urbano, Regional, Integrado, Sustentável. Braga. 2006. p. 1-12.

SANTOS, M. Por uma geografia nova. $4^{a}$ ed. São Paulo: Hucitec, 1996. p. 203-12.

SANTOS, M. A natureza do espaço: técnica e tempo, razão e emoção. $4^{a}$ ed. São Paulo: Editora da Universidade de São Paulo, 2012.

SILVA, A. A. D.; GALENO, A. Geografia: ciência do complexus: ensaios transdiciplinares. Porto Alegre: Sulina, 2004.

SUERTEGARAY, D. M. A. A trajetória da natureza: Um estudo geomorfológico sobre os areais de Quaraí-RS. São Paulo, 1988. 243p. Tese (Doutorado em Geografia Física com ênfase em Geomorfologia) - Faculdade de Filosofia, Letras e Ciências Humanas, Universidade de São Paulo.

SUERTEGARAY, D. M. A.; NUNES, J. O. R. A natureza da Geografia Física na Geografia. Revista Terra Livre, no 17, $2^{\circ}$ semestre. São Paulo, Associação dos Geógrafos Brasileiros, 2001.

VÁZQUES, A. S. Filosofia da práxis. Buenos Aires: Consejo Latiamericano de Ciencias SocialesCLACSO; São Paulo: Expressão Popular, 2007.

WHITEHEAD, A. N. O conceito de natureza. São Paulo: Martins Fontes, 1993. 